\title{
Sexual Dimorphism of Viscerocranium-A Logistic Model
}

Lucas del Vigna Peixoto ${ }^{1}$, Stefany de Lima Gomes ${ }^{1}$, Ana Amelia Barbieri $^{1}$, Francisco Carlos Groppo ${ }^{1}$, Cristhiane Martins Schmidt ${ }^{1}$, Viviane Ulbricht ${ }^{1}$, Carlos Sassi ${ }^{1}$, Joao Cesar Bedran de Castro ${ }^{1}$, Rachel Tinoco ${ }^{2}$, Eduardo Daruge Junior ${ }^{1}$, Luiz Francesquini Junior $^{1 *}$

${ }^{1}$ Univeridade Estadual de Campinas, Brazil

${ }^{2}$ UFRJ National Museum. Brazil

*Corresponding author: Luiz Francesquini Junior: francesq@unicamp.br

\section{OPEN ACCESS}

Citation: Peixoto L.V., Gomes S.L. , Barbieri A.A., Groppo F.C., Schmidt C. M., Ulbricht V., Sassi C., Castro J.C.B, Tinoco R. Junior E.D., Junior L.F.(2021) Sexual Dimorphism of Viscerocranium - A Logistic Model. Open Science Journal 6(2)

Received: $6^{\text {th }}$ December 2020

Accepted: $9^{\text {th }}$ February 2021

Published: 28 th April 2021

Copyright: (C) 2021 This is an open access article under the terms of the Creative Commons Attribution License, which permits unrestricted use, distribution, and reproduction in any medium, provided the original author and source are credited.

Funding: The author(s) received no specific funding for this work

Competing Interests: The author has declared that no competing interests exists.

\section{Abstract:}

Introduction: Sex estimates are generally based on the evaluation of qualitative and quantitative aspects of anatomic structures, however, the latter has better reproducibility and reliability. Objective: Aiming to evaluate the viscerocranium as a tool for sexual prediction and verify the possibility of creation of a logistic regression model for sexual prediction. Materials and Methods: 167 craniums - 100 male and 67 female between 22 and 85 years old from a Brazilian university's Biobank - were evaluated. Results: It was observed that of the measures carried out were presented as sexually dimorphic, except for the measures of the right frontozygomatic point - right zygion; left frontozygomatic point - left zygion. Besides, it was possible to create a logistic regression model Sex $=[\operatorname{logits} / \mathrm{Sex}=-24.5+$ $(0.20 *$ Nasion - Naso spine $)+(0.18 *$ Right zygion - Naso spine)]. Conclusion: It was concluded that the measures of the viscerocranium present themselves as a factor of sexual dimorphism and the quantitative method developed was $81.4 \%$ accurate.

Keywords: Forensic dentistry, Sex determination by skeleton, Forensic anthropology, Facial bones, Logistic models. 


\section{Introduction}

The face is a very important part of the human body because it expresses ancestry, sex, and age of individuals, as well as emotions and part of the human psyque $[1,2]$. A great part of this expression is due to the osseous framework, developed through hormonal influence during adolescence, named somatic sex, influenced by, inter alia, the local environment, nutrition, practice of physical exercise, and genetics. These influences are vital to adaptation and survival of different population groups and make their measures and anatomic angles more peculiar. Regionalized research allow, thus, for more reliable and effective measurements in anthropological evaluations.

Studies point to the fact of the cranium being, overall, the most commonly found body part, both in crime scenes and in places of mass-casualty accidents $[2,3]$. Moreover, its characteristics regarding sexual dimorphism are significant, what makes accurate results for sexual prediction possible [4-8].

Physical anthropometry is considered by Interpol [9] the secondary method in disaster victims identification, as it is used once other methods of human identification are not viable, such as in cases of carbonized bodies, bodies in an advanced state of decomposition or mutilated bodies. The data collected is used to trace profiles and decrease the number of possible victims, accelerating the process of human identification.

The forensic anthropologic method for estimating age and sex via measurements of osseous structures - the somatometric method - provides mathematical precision and allows the reproducibility of information in addition to practicality in execution [10].

The logistic regression allows the estimation of the probability of the dependent variable assuming a determined value when there are other known variables, which facilitates individual classification in categories and providing results in probabilities with high reliability.

The benefit of the attainment of a logistic regression model for the cranial facial area that uses only two measures of the viscerocranium is that it enables sex determination in a secure and fast manner, with no need for costly examinations and equipments, serving, therefore, any professional, regardless of institution and context.

The present study sought to create a logistic regression model for sexual prediction and analyse sexual dimorphism of some measures of the viscerocranium: from the right frontozygomatic point to the left frontozygomatic point, from the left frontozygomatic point to the left zygion, from the right frontozygomatic point to the right zygion, from the right zygion to naso spine, from the left zygion to naso spine, from nasion to naso spine (nasal height), and maximum width of the piriformis (nasal width).

\section{Materials and methods}

\section{Sample composition}

This is an analytical cross-sectional observational study based on the collection of skeletal remnants of the Osteological and Tomographic Biobank Prof. Eduardo Daruge of FOP/UNICAMP, with skeletons of both genres -67 
women and 100 men - aged between 22 and 85 years. The sample calculation was done based on the population estimates for Brazilian Municipalities and Federation Units, made by the Brazilian Institute of Geography and Statistics, which indicated the population of the state of São Paulo to be 45.538.936 inhabitants. As a result of the sample calculation for the obtention of valid data, based on the aforesaid population and considering a $90 \%$ trust level and a $5 \%$ margin of error. The exclusion criteria were: all the skeletons were from Brazilians, aged over 22 years old, without anomalies or pathologies that could interfere with the metric analysis.

\section{Measurements studied}

An examiner made the following linear measurements, using a precision digital caliper (Stainless ${ }^{\circledR}$ - hardened $150 \mathrm{~mm}$, Mauá, São Paulo, Brazil), as shown in Figure 1, namely:

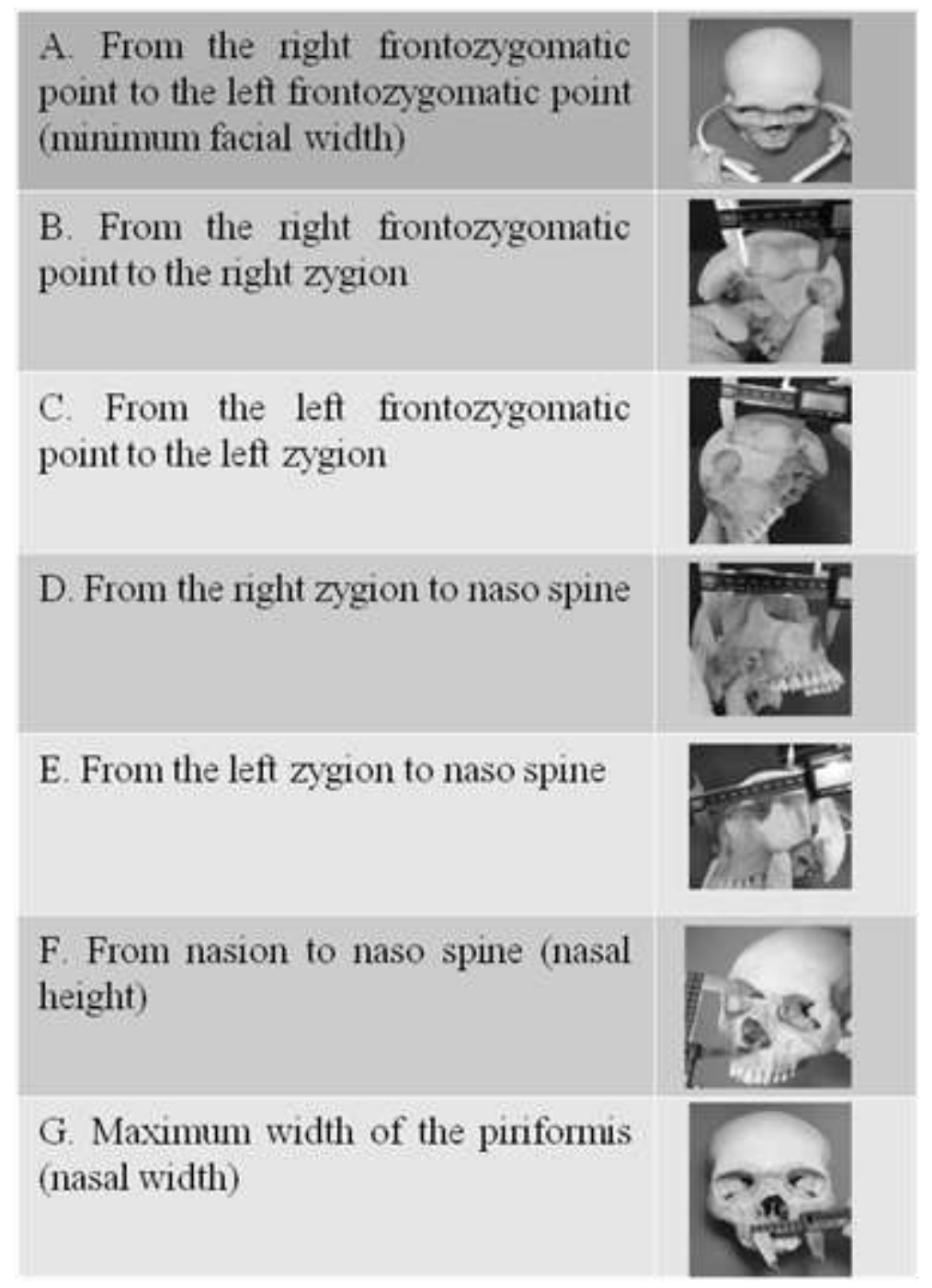

Figure 1 - Measures evaluated in the viscerocranium

\section{Ethics evaluation}


This study was approved by the Human Research Ethics Committee and is in agreement with the resolution 466/12 with approval of the CEP/FOP/UNICAMP 138/2014 CAAE 38522714.6.0000.5418, opinion number 1.900 .981 .

\section{Intra and intercalibration examiner}

To start the measurements, the inter- and intracalibration was performed using the intraclass correlation test, as shown in Table 1. It was performed in three different periods in 25 skeletons, with a one-month interval between them.

Table 1. Intraclass correlation test (ICC) for intra-examiner reproducibility.

\begin{tabular}{|c|c|c|c|}
\hline Measures & $\mathrm{ICC}$ & $\mathrm{P}$ & Result \\
\hline $\begin{array}{l}\text { Frontozygomatic point }(\mathrm{R})- \\
\text { Frontozygomatic point }(\mathrm{L})\end{array}$ & $\begin{array}{c}0.99 \\
54 \\
\end{array}$ & $\begin{array}{c}\mathrm{p}< \\
0.0001 \\
\end{array}$ & excellent reproducibility \\
\hline Frontozygomatic point (L) - Zygion (L) & $\begin{array}{c}0.94 \\
95\end{array}$ & $\begin{array}{c}\mathrm{p}< \\
0.0001\end{array}$ & excellent reproducibility \\
\hline Frontozygomatic point (R) - Zygion $(\mathrm{R})$ & $\begin{array}{c}0.96 \\
22\end{array}$ & $\begin{array}{c}\mathrm{p}< \\
0.0001\end{array}$ & excellent reproducibility \\
\hline Zygion (R) - Naso spine & $\begin{array}{c}0.95 \\
93\end{array}$ & $\begin{array}{c}\mathrm{p}< \\
0.0001\end{array}$ & excellent reproducibility \\
\hline Zygion (L) - Naso spine & $\begin{array}{c}0.99 \\
35\end{array}$ & $\begin{array}{c}\mathrm{p}< \\
0.0001\end{array}$ & excellent reproducibility \\
\hline Nasion - Naso spine & $\begin{array}{c}0.98 \\
15\end{array}$ & $\begin{array}{c}\mathrm{p}< \\
0.0001\end{array}$ & excellent reproducibility \\
\hline Maximum width of the piriformis & $\begin{array}{c}0.80 \\
41\end{array}$ & $\begin{array}{c}\mathrm{p}< \\
0.0001\end{array}$ & excellent reproducibility \\
\hline
\end{tabular}

At the end of this step, and calibrated, the other skulls were measured to totalize 167 skulls, whose sex, age, and ancestry were known, among other existing information.

\section{Statistical analysis of the data obtained}

Data analysis was performed using the Kolmogorov-Smirnov \& Levene test and unpaired t test. For logistic regression, the backward stepwise (Wald) was used. Hosmer \& Lemeshow and Nagelkerke test was also used. The GRAPHPAD PRISM 7.0 was the software used.

\section{Results}

The Kolmogorov-Smirnov and Levene tests showed the data presented, respectively, normality (after transformation) and homoscedasticity; thus, the unpaired $t$ test was applied to compare both sexes considering each measure separately, as shown in Table 2. 
Table 2. Values (mean \pm standard error) of the measures according to sex.

Sex

Male $(\mathrm{n}=100) \quad$ Female $(\mathrm{n}=67) \quad \mathrm{P}$

A - Frontozygomatic point (R) - Frontozygomatic

$102.7( \pm 0.47)$

$99.4( \pm 0.51)$

$<0.0001$

point (L)

B - Right frontozygomatic point - Right zygion

$44( \pm 0.59)$

$42.4( \pm 0.62)$

0.0663

C - Left frontozygomatic point - Left zygion

$43.9( \pm 0.31)$

$42.8( \pm 0.59)$

0.064

\begin{tabular}{ccc}
\hline D - Right zygion - Naso spine & $85.2( \pm 0.46)$ & $80.2( \pm 0.55)$ \\
\hline E - Right zygion - Naso spine & $85.6( \pm 0.48)$ & $79.8( \pm 0.83)$ \\
\hline F - Nasion - Naso spine & $51.2( \pm 0.55)$ & $47.3( \pm 0.41)$ \\
\hline Maximum width of the piriformis & $25.3 \pm 0.24$ & $24.3( \pm 0.26)$
\end{tabular}

The table reveals clear sexual dimorphism in the measures, and the measures right frontozygomatic point - left frontozygomatic point, right zygion - naso spine, left zygion - naso spine, nasion - naso spine, and maximum width of the piriformis were greater for men. However, the measures right frontozygomatic point - right zygion, and left frontozygomatic point - left zygion were similar between sexes.

To observe the influence of sex on the measures, logistic regression (Forward Stepwise-Wald) was calculated, considering " 1 " for male and " 0 " for female, for calculation purposes.

Regression showed the model composed of the measures D (right zygion - naso spine) and $\mathrm{F}$ (nasion - naso spine) were the best (Chi-square $=53.7, \mathrm{p}<0.0001)$ to predict sex. The measures $\mathrm{A}(\mathrm{p}=0.21), \mathrm{B}(\mathrm{p}=0.59), \mathrm{C}(\mathrm{p}=0.81), \mathrm{E}(\mathrm{p}=0.17)$ and $\mathrm{G}(\mathrm{p}=0.30)$ were not relevant to the model. The Nagelkerke $\mathrm{R}^{2}$ showed the variables are responsible for $38.2 \%$ of the variation found in sex. In addition, the Hosmer-Lemeshow test showed the model was adequate $(\mathrm{p}=0.13)$. Table 3 shows this model.

Table 3. Logistic regression for sex, considering the variables under study.

\begin{tabular}{|c|c|c|c|c|c|}
\hline & \multicolumn{3}{|c|}{ Standard } & \multirow{3}{*}{ p-Value } & Coefficient \\
\hline & \multirow[t]{2}{*}{ coefficient } & & \multirow[t]{2}{*}{ Wald } & & \multirow[b]{2}{*}{ Standardized } \\
\hline & & error & & & \\
\hline D - Right zygion - Naso spine & 0.18 & 0.05 & 15.67 & $<0.0001$ & 1.20 \\
\hline F - Nasion - Naso spine & 0.20 & 0.06 & 10.39 & 0.0012 & 1.22 \\
\hline
\end{tabular}




$<0.0001$

The logits was obtained:

Logistic regression model [Sex $=-24.5+(0.20 *$ Nasion - Nasio spine $)+(0.18$ × Right zygion - Naso spine)].

Values higher than 0.5 (cutoff point) would be considered "male" and lower, "female." Table 4 shows the prediction considering this relation.

Table 4. Prediction of sex by applying logistic regression.

Prediction using the formula

Female
Male

Correct percentage

\begin{tabular}{ccccc}
\hline Sex & Female & 47 & 19 \\
\hline Male & 11 & 84 & \\
\hline & & Correct overall percentage & \\
\hline
\end{tabular}

This table shows the method results in $88.4 \%$ sensitivity, $71.2 \%$ specificity, and $81.3 \%$ accuracy, thus proving to be more effective in the sex prediction.

\section{Discussion}

Sexual dimorphism from the analysis of skeletal human remains is a fundamental step in forensic investigation. Men and women show different characteristics such as hormonal and skeletal physiology that correspond to sexual dimorphism. The skeletal characteristics have the advantage of resisting a long time after death, allowing for analysis for sexual differentiation. Authors assert [2,4,5-8] based on their studies that the certainty degree of the sexual diagnosis varies according to the number and nature of the elements analysed. When only the hipbone is used for analysis, the probability of correctness is $95 \%$, whilst when only the cranium is used, $92 \%$, and when analysed together, the process reaches $98 \%$ probability of being correct [11].

One of the branches of forensic anthropology is sex determination through osseous analysis. Usually, metric and morphologic methods are used to determine sexual dimorphism. The advantage held by the metric method lies in its mathematical precision, given that it generates equations, deriving of measures acquired by a safe, practical and reproducible methodology, besides being more objective $[6,12]$.

The present study assessed measures of the viscerocranium for sexual prediction and the results acquired allow one to infer that five of the measures studied are dimorphic and two of them (right frontozygomatic point - right zygion, and left frontozygomatic point - left zygion) are not adequate for sex determination. It is suggested, regarding the small difference between men and women in those two measures (left and right sides), that this could be justified by the large intermingling existent in Brazil, which would have caused modifications in the characteristics that would be distinguishable among the different 
ethnicities, therefore allowing for less sexual differentiation. Such situation was also found by Steyn \& Iscan [13], in which they verified that the bizygomatic measure was the most dimorphic among the 91 evaluated skeletons from the Pretoria and Witwatersand Collection.

The authors believe that if the sample was composed of less intermingled individuals, such as indigenous and quilombo, a difference of 2 to $4 \%$ higher in males compared to females would be observed. This is supported by the studies of Zaki et al. [14] that, by measuring 149 cephalometrics obtained from Libia's archaeological sites, verified that the studied craneous measures of individuals who had not gone through much intermingling were larger in males in the order of $8.5 \%$ when compared to female craniums. Only the anterior nasal spine to posterior nasal spine measure was not considered dimorphic. Also, Naikmasur et al. [15], studying 105 radiographic images of Tibetan and South Indian individuals, observed an accuracy level of $81.5 \%$ for South Indians and $88.2 \%$ for Tibetans. The most dimorphic measurements found are the bizygomatic width, the ramus height and face depth.

It was possible to create a logistic regression model $[\mathrm{Sex}=-24.5+(0.20 \times$ Nasion - Nasio spine $)+(0.18 *$ Right zygion - Naso spine $)]$ to determine sex, with level of accuracy of $81.4 \%$. This datum corroborates the findings by Almeida Júnior et al. [16], who studied the transverse index - maximum height and width, obtaining level of accuracy of $76.25 \%$ by using discriminant analysis and $81.50 \%$ through regression. Also with little variation, Francesquini Jr. et al. [17], who studied the skull base, obtained level of accuracy of $78.2 \%$ using logistic regression.

In the same norma basalis used by Uthaman, Al-Rawi \& Al-Timimi [18], the foramen magnum (its length and width) was studied, obtaining level of accuracy of $67 \%$ by using discriminant analysis and $69.3 \%$ using multiple regression. Jain, Jasuja \& Nath [19] assessed the length of the foramen magnum, obtaining level of accuracy of $75.5 \%$. In turn, Franklin, Freedman \& Milne [20] obtained level of accuracy from $77 \%$ to $80 \%$, and the facial width was the most discriminant. Also, Oliveira et al. [21] found using the bizygomatic measurement and measures of basal lambda in a regression model with the data from a file of bones of Cuiabá, obtaining level of accuracy of $72 \%$ was possible.

One believes that obtaining a level of accuracy close to $100 \%$ is possible only when the mathematical model for sex determination in bone collections whose representatives are highly dimorphic (big male skulls and small female skulls), not representative of the current population. The Brazilian and European populations has from 10 to $20 \%$ of undifferentiated skulls [3]. This fact can explain the findings by Mahakkanukrauh [22], who obtained 91.4\%.

It is emphasized that studies that present discordant results from this study cannot be found in Brazilian literature. Besides, the linear measurements choice made in this study are also not listed in literature, which denotes that this is an unprecedented study.

The current Brazilian population, due to intermingling, has a difference as to ancestrality. The Brazilian Institute for Geography and Statistics (IBGE)22 presents Brazilian ethnic distribution as the following: white (45.5\%), brown (45\%), black (8.6\%), and other groups (0.9\%). Such data are very coincident with the sample of the present research and very representative of the current Brazilian population, namely: white $(58.75 \%)$, brown $(27.81 \%)$, black $(13.12 \%)$, and asiatican $(0.32 \%)$. 


\section{Conclusion}

The viscerocranium has presented itself as an effective tool in sexual prediction once five of the measurements taken were considered sexually dimorphic, except for the frontozygomatic point - right zygion; left frontozygomatic point - left zygion. Two measures have shown greater sexual dimorphism, and were used for the creation of a logistic regression model to determine the sex $[$ logits $/$ Sex $=-24.5+(0.20 *$ Nasion - Naso spine $)+(0.18 *$ Right zygion - Naso spine)]. The quantitative method developed results in level of accuracy of $81.4 \%$.

\section{Acknowledgments}

The authors thank Mr. João Leite for his enormous contribution to the preanalysis processing of the skeletal remnants of the collection used.

They thank the $\mathrm{CNPq} / \mathrm{SAE}$ for the scientific initiation scholarship.

\section{References:}

1.Tinoco, RLR; Lima, LNC; Fernandes MM; Francesquini Júnior, L; Daruge, E. The use of dental dimensions estimated from personal portraits in human identification. Brazilian Journal of Oral Sciences (Print), 2011; 10: 158-162.

2.Daruge, E. Daruge Jr., E., Francesquini Jr., L. Tratado de Odontologia Legal e Deontologia. São Paulo: Editora Santos - Gen, 1.ed., 2017.

3.Harma A, Karakas HM Determination of sex from the femur in Anatolian Caucasians; a digital radiological study. J. Clin. Forensic Med., January, 2007; 17:147-183.

4.Rogers, T.L. Determining the sex of human, remains trough cranial morphology. Journal Forensic Sciences, May (2005);50(3): 493-500.

5.França C; Cunha HM; Barbieri AA; Assis ACS; Manhães Junior LRC; Lopes SLPC. TMJ dimensions in three-dimensional virtual models acquired through computed tomography of cone beam as sexual dimorphism. Braz Dent Sci 2017; 20:34-43.

6.Asghar A, Dixit A, Rani M. Morphometric Study of Nasal Bone and Piriform Aperture in Human Dry Skull of Indian Origin. J Clin Diagn Res. 2016 Jan;10(1):AC05-7.

7.Kanchan T, Gupta A, Krishan K. Craniometric analysis of foramen magnum for estimation of sex. Int J Med Phar Sci Eng. 2013;7(7).

8.Kanchan T, Gupta A, Krishan K. Estimation of sex from mastoide triangle - a craniometrics analysis. J Forensic Leg Med. 2013;20(7):855-860.

9.Interpol $\quad-\quad$ Disaster Victim identification guide file://C:/Users/Usu\%C3\%A1rio/Downloads/guide[1].pdf [access February 7, 2019]

10.Barbieri AA, Bonfiette D, Borges JLC, Oliveira E, Assis ACS, Manhães Junior LRC, Lopes SLPC. Evaluation of the mandibular notch angle in three-dimensional virtual models as a parameter for determining age and sexual dimorphism. Braz Dent Sci; 21:424 -28.

11.Delwing F. Análise do dimorfismo sexual em adultos através de medidas cranianianas, dissertação - Faculdade de Odontologia de Piracicaba, da Universidade Estadual de Campinas, 2013.

11.Bidmos MA, Asala SA. Discriminant function sexing of the calcaneus of the South Africa whites. J Forensic Sci. 2003; 48(6): 1-6.

12.Steyn M, Iscan MY. Sexual dimorphism in the crania and mandibles of South African whites. Forensic Science International. 98(1998):9-16.

13.Zaki ME, Soliman MA, El-Bassyouni HT. A cephalometric study of skulls from the bahriyah oasis. J Forensic Dent Sci. 2012; 4(2):88-92.

14.Naikmasur VG, Shrivastava R, Mutalik S. Determination of Sex in South Indians and Immigrant Tibetans From Cephalometric Analysis and Discriminant Functions. Forensic Science International. 2010; 197: 122.e1 - 122.e6.

15.Almeida Júnior E, Reis FP, Galvão LCC, Alves MC, Cabral ARJ, Teixeira S. Estimativa do sexo e idade por meio do índice transverso em crânios secos de adultos. Rev Bahiana Odontol. 2013; $4(2): 85-95$. 
16.Francesquini Júnior L, Francesquini MA, De La Cruz SDR, et al. Use of cranial measurements to predict sex. J Forensic Odonto-Stomatology, 2007; 25(1): 1-5.

17.Uthaman A, Al-Rawi N, Al-Timimi J. Evaluation of foramen magnum in gender determination using helical CT scanning. Dentomaxillofac Radiol 2012;41(3):197-202.

18.Jain D, Jasuja O, Nath S. Evaluation of foramen magnum in sex determination from human crania by using discriminant function analysis. El Med J. 2011;2(2):89-92.

19.Franklin D, Freedman L, Milne N. Sexual dimorphism and discriminant function sexing in indigenous South African crania. HOMO - Journal of Comparative Human Biology. 2005; 55(2005):213-228.

20. Oliveira OF, Tinoco RLR, Daruge Júnior E, Terada ASSD, Alves da Silva RH, Paranhos LR. Sexual Dimorphism in Brazilian Human Skulls: Discriminant Function Analysis. JFOS. 2012, $30(2): 26-33$.

21.Mahakkanukrauh P, Sinthubua A, Prasitwattanaseree S, Ruengdit S, Singsuwan P, Praneatpolgrang S, Duangto P. Craniometric study for sex determination in a Thai population. Anat Cell Biol. 2015;48(4):275-83.

22.Romildo J. População brasileira é formada basicamente de brancos e pardos, diz IBGE. http://agenciabrasil.ebc.com.br/economia/noticia/2015-11/populacao-brasileira-e-formadabasicamente-de-brancos-e-pardos-diz-ibge [acces on 2018 feb 24]. 